\title{
Comparação dos perfis bioquímicos e hematológicos de pacientes com COVID-19 em seus diferentes desfechos: alta hospitalar e óbito
}

\author{
Comparison of the biochemical and hematological profiles of patients with COVID-19 in their \\ different outcomes: Hospital discharge and death
}

Comparación de perfiles bioquímicos y hematológicos de pacientes con COVID-19 en sus diferentes desenlaces: alta hospitalaria y muerte

\author{
Gabriel Frateschi Rebello da Silva \\ ORCID: https://orcid.org/0000-0002-5236-256X \\ Universidade São Judas Tadeu, Brasil \\ E-mail: gabrielfrateschi115@gmail.com \\ Alexandra Alejo Callante \\ ORCID: https://orcid.org/0000-0002-3453-7274 \\ Universidade São Judas Tadeu, Brasil \\ E-mail: alexandracallante@gmail.com \\ Débora Pereira do Nascimento \\ ORCID: https://orcid.org/0000-0002-7781-1405 \\ Universidade São Judas Tadeu, Brasil \\ E-mail: debora_pn92@hotmail.com \\ Iago Portolani de Araujo \\ ORCID: https://orcid.org/0000-0002-3197-6474 \\ Universidade São Judas Tadeu, Brasil \\ E-mail: iagoportolani@hotmail.com \\ Carolina Heitmann Mares Azevedo Ribeiro \\ ORCID: https://orcid.org/0000-0002-9457-2733 \\ Universidade Federal do Pará, Brasil \\ E-mail: chribeiro@ufpa.br \\ Ana Cristina Lo Prete \\ ORCID: https://orcid.org/0000-0002-2874-5296 \\ Universidade São Judas Tadeu, Brasil \\ E-mail: analoprete@gmail.com
}

\begin{abstract}
Resumo
Introdução: O vírus causador da COVID-19, SARS-CoV-2, apresenta como principal foco de comprometimento o trato respiratório, ainda hoje com muitos pacientes evoluindo para a forma mais grave. Por isso, deve-se identificar precocemente sinais e sintomas da COVID-19, além de possíveis fatores de risco e sinais de mau prognóstico envolvidos na progressão da doença. Objetivo: Desta forma, o presente trabalho teve por objetivo avaliar exames bioquímicos, hematológicos e de coagulação em pacientes diagnosticados com a COVID-19, a fim de identificar um padrão de prognóstico para os desfechos de alta hospitalar e óbito a partir de um compilado de dados descritivos de um repositório público. Metodologia: dados de pacientes atendidos entre 26 de fevereiro e 27 de junho de 2020 no Hospital Sírio-Libanês, disponibilizado por um repositório público, foram divididos em duas categorias para análises. Foram analisados os dados demográficos (gênero, idade e cidade onde o paciente reside) e dados clínicos/laboratoriais (resultados de exames), incluindo o desfecho (alta ou óbito). Resultados: Idade mais avançada e gênero masculino foram mais associados com o desfecho de óbito. Dímero-D e glicemia foram mais altas no grupo óbito, enquanto a TFG apresentou piora em ambos os grupos e TTPA, bilirrubina total, creatinina sérica, glicemia, dímero-D e PCR aumentaram no desfecho apenas dos pacientes que vieram à óbito, tendo esse último reduzido no grupo "alta hospitalar". Além disso, houve menores índices de hemoglobina, eritrócitos e hematócrito, plaquetas e linfócitos, assim como aumento de leucócitos, neutrófilos e basófilos no grupo de pacientes que evoluiu para óbito. Conclusão: As variações encontradas nos parâmetros bioquímicos sugerem especialmente que a hiperglicemia está associada a casos mais graves, enquanto a análise de inflamação confirma pela PCR que esta condição foi mais exacerbada nos pacientes que morreram. $\mathrm{Na}$ análise de coagulação, o aumento do dímero-D foi associado a quadros mais graves e, nos hematológicos, os resultados refletem maior risco de anemia e resposta inflamatória sistêmica.
\end{abstract}

Palavras-chave: SARS-CoV-2; COVID-19; Biomarcadores; Prognóstico. 


\begin{abstract}
Introduction: The virus that causes COVID-19, SARS-CoV-2, has as its main focus of involvement the respiratory tract, even today with many patients evolving to the most severe form. Therefore, it is necessary to identify early signs and symptoms of COVID-19, as well as possible risk factors and signs of poor prognosis involved in the progression of the disease. Objective: The present study aimed to evaluate biochemical, hematological and coagulation tests in patients diagnosed with COVID-19 in order to identify a prognostic pattern for the outcomes of hospital discharge and death from a descriptive data compilation from a public repository. Methodology: Data from patients seen between February 26 and June 27, 2020 at Hospital Sírio-Libanês, made available by a public repository, were divided into two categories for analyses. Demographic data (gender, age and city where the patient resides) and clinical/laboratory data (test results) were analyzed, including the outcome (discharge or death). Results: Older age and male gender were more associated with the outcome of death. D-dimer and blood glucose were higher in the death group, while GFR worsened in both groups and APTT, total bilirubin, serum creatinine, blood glucose, D-dimer and CRP increased in the outcome only of patients who died, the latter reduced in the "hospital discharge" group. Moreover, there were lower rates of hemoglobin, erythrocytes and hematocrit, platelets and lymphocytes, as well as increased leukocytes, neutrophils and basophils in the group of patients who died. Conclusion: The variations found in biochemical parameters suggest especially that hyperglycemia is associated with more severe cases, while the analysis of inflammation confirms by CRP that this condition was more exacerbated in patients who died. In coagulation analysis, increased D-dimer was associated with more severe cases, and in hematology, the results reflect a higher risk of anemia and systemic inflammatory response.
\end{abstract}

Keywords: SARS-CoV-2; COVID-19; Biomarkers; Prognosis.

\title{
Resumen
}

Introducción: El virus causante del COVID-19, el SARS-CoV-2, presenta como principal foco de compromiso el tratamiento respiratorio, aún hoy con muchos pacientes evolucionando hacia la forma más grave. Por lo tanto, los signos y síntomas de la COVID-19 deben identificarse de forma temprana, además de los posibles factores de riesgo y signos de mal pronóstico implicados en la progresión de la enfermedad. Objetivo: Por lo tanto, el presente estudio tuvo como objetivo evaluar las pruebas bioquímicas, hematológicas y de coagulación en pacientes diagnosticados de COVID-19 con el fin de identificar un patrón pronóstico para los resultados de alta hospitalaria y muerte a partir de una recopilación de datos descriptivos de un repositorio público. Metodología: los datos de los pacientes atendidos entre el 26 de febrero y el 27 de junio de 2020 en el Hospital Sirio-Libanés, puestos a disposición por un repositorio público, fueron divididos en dos categorías para su análisis. Se analizaron los datos demográficos (sexo, edad y ciudad de residencia del paciente) y los datos clínicos/laboratorios (resultados de las pruebas), incluido el resultado (alta o muerte). Resultados: La edad avanzada y el sexo masculino se asociaron más con el resultado de muerte. El dímero D y la glucemia fueron más elevados en el grupo de muerte, mientras que la TFG empeoró en ambos grupos y el TTPA, la bilirrubina total, la creatinina sérica, la glucemia, el dímero D y la PCR aumentaron en el desenlace sólo en los pacientes que murieron, reduciéndose esta última en el grupo de "alta hospitalaria". Además, había tasas más bajas de hemoglobina, eritrocitos y hematocrito, plaquetas y linfocitos, así como un aumento de leucocitos, neutrófilos y basófilos en el grupo de pacientes que murieron. Conclusión: Las variaciones encontradas en los parámetros bioquímicos sugieren especialmente que la hiperglucemia está asociada a los casos más graves, mientras que el análisis de la inflamación confirma por PCR que esta condición estaba más exacerbada en los pacientes que murieron. En los análisis de coagulación, el aumento del dímero D se asoció a cuadros más graves y, en los hematológicos, los resultados reflejan un mayor riesgo de anemia y de respuesta inflamatoria sistémica.

Palabras clave: SARS-CoV-2; COVID-19; Biomarcadores; Pronóstico.

\section{Introdução}

Em 31 de dezembro de 2019 foram relatados em Wuhan, na China, casos de pneumonia grave em decorrência de doença respiratória de origem desconhecida (R. Chen et al., 2020; Ashour et al., 2020). O Centro Chinês de Controle e Prevenção de Doenças (CDC) conseguiu, no dia 7 janeiro de 2020, com auxílio da tecnologia de sequenciamento, isolar e identificar o patógeno responsável pela série de casos de pneumonia. A doença é causada por um vírus denominado Coronavírus da Síndrome Respiratória Aguda Grave 2 (SARS-CoV-2) que em seguida, recebeu o nome de COVID-19 pela Organização Mundial da Saúde (OMS) (R. Chen et al., 2020; Ge et al., 2020; Zhang, 2020).

Os Coronavírus humanos são caracterizados por vírus de ácido ribonucleico (RNA) de fita simples, que apresentam proteínas estruturais como Spike (S), Nucleocapsídeos (N), Matrix (M) e Envelope (E). O vírus utiliza a proteína S (Spike) como forma de reconhecimento para a sua fixação, e posteriormente, entrada na célula hospedeira (Ibrahim et al., 2020). 
Classificado como o terceiro Coronavírus humano zoonótico, o SARS-CoV-2 é similar ao da síndrome respiratória aguda grave Coronavírus (SARS-CoV), que surgiu em novembro de 2002 em Guangdong, China, e ao da síndrome respiratória Coronavírus do Oriente Médio (MERS-CoV), que atingiu a Arábia Saudita, no ano de 2012 (Baloch et al., 2020; Gralinski \& Menachery, 2020).

Devido à acelerada propagação da infecção, na medida em que o grau de complexidade da doença aumentou, a OMS declarou oficialmente uma pandemia em março de 2020 (Maciel et al., 2020; Ge et al., 2020; Holshue et al., 2020; Tian et al., 2020).

Desde seu aparecimento em 2019, já foram notificados à OMS 228.807.631 casos confirmados de COVID-19 no mundo, com 4.697.099 mortes. Em comparação com os outros países avaliados, atualmente o Brasil ocupa a terceira posição em relação ao número de casos confirmados, contabilizando 21.239.783, e possuindo o segundo maior número de mortes, 590.752 ao total, de acordo com os dados da última atualização em 21 de setembro de 2021 (OMS, 2020).

A transmissão da SARS-CoV-2 ocorre através de indivíduos infectados por meio de contato próximo, gotículas de saliva, espirro, tosse e objetos ou superfícies que estejam contaminadas (Ministério da Saúde, 2020). A probabilidade de infecção é maior entre mulheres grávidas, idosos com comorbidade, imunodeficientes e indivíduos expostos a uma grande carga viral (Yi et al., 2020).

Embora o vírus seja parecido com os anteriores, o principal foco da SARS-CoV-2 é o trato respiratório e, comumente os indivíduos infectados acabam evoluindo para a forma mais grave em aproximadamente 10 - $20 \%$ dos casos, precisando de internação hospitalar ou tratamento em unidade de terapia intensiva (UTI) (Bourgonje et al., 2020).

A infecção pelo SARS-COV-2 pode desencadear graves problemas pulmonares e cardíacos, o que geralmente é a causa do óbito. Por isso, deve-se identificar precocemente sinais e sintomas da COVID-19 (B. Wang et al., 2020), além de possíveis fatores de risco e sinais de mau prognóstico envolvidos na progressão da doença (Wang et al., 2020; Mizumoto, 2020), para assim impedir o seu avanço, tanto pela identificação de dados clínicos, quanto laboratoriais (Wang et al., 2020; Jain \& Yuan, 2020).

Além do avanço da idade e do gênero masculino, os quais estão envolvidos com aumento da letalidade (Yan et al., 2020; Jain \& Yuan, 2020), existem diversos estudos relacionando a gravidade do quadro da COVID-19 com a pré-existência de outras doenças e condições clínicas.

Entre os dados clínicos, embora ainda pouco conhecidos, foram encontradas evidências de que muitos pacientes infectados gravemente pela COVID-19 apresentavam a coexistência de condições crônicas, sendo as mais descritas a asma e pneumonias, imunodeficiências, diabetes, hipertensão, obesidade, doenças hematológicas, neurológicas, renais, cardiovasculares, síndrome de Down e hipertensão arterial, os quais apresentam, portanto, um prognóstico ruim (Callender et al., 2020; Sousa et al., 2020).

Nesta busca por marcadores de mau prognóstico, os testes laboratoriais vêm sendo investigados por diversos autores.

Uma vez que o processo inflamatório pulmonar é a principal manifestação clínica da COVID-19, estudos vêm sendo realizados para avaliar essa inflamação característica do quadro, em pacientes com ela pré-existente ou não, e suas consequências biológicas. Para tanto, a avaliação de proteínas inflamatórias (ex. proteína $\mathrm{C}$ reativa) e citocinas inflamatórias, assim como suas consequentes alterações no perfil hematológico, podem indicar danos teciduais e celulares (Ponti et al., 2020), e informar sobre o prognóstico do quadro.

Outros testes laboratoriais, como a determinação do dímero-D, transaminases (Ponti et al., 2020; Xavier et al., 2020), VHS (Velocidade de Hemossedimentação), entre outros testes que compõem o perfil bioquímico, hematológico e de coagulação, estão sendo investigados em pacientes com a COVID-19 na busca de identificar marcadores de prognóstico da doença (Xavier et al., 2020; Liu et al., 2020). 
Desse modo, é de extrema relevância a realização do presente trabalho para complementar os dados investigativos a respeito de exames laboratoriais como ferramentas de identificação de prognóstico de quadros de COVID-19 na população brasileira.

\section{Metodologia}

Para o desenvolvimento do presente trabalho foi realizada uma busca de dados de pacientes infectados por SARSCoV2, disponibilizados em um repositório público "COVID-19 Data Sharing/BR" da Fundação de Amparo de Pesquisa do Estado de São Paulo (FAPESP) em cooperação com a Universidade de São Paulo (USP) e, participação do Instituto Fleury, Hospital Sírio-Libanês e Hospital Israelita Albert Einstein (https://repositoriodatasharingfapesp.uspdigital.usp.br/).

Os estudos com análises de bancos de dados públicos têm sido muito utilizados, em especial, na análise de pacientes COVID-19, pois fornecem informação práticas de um número muito elevado de pacientes (Maciel et al., 2021; Ranzani et al., 2021).

A finalidade do repositório foi viabilizar informações que contribuíssem para a pesquisa desta temática, tendo sido disponibilizado dados de pacientes atendidos do dia 26 de fevereiro a 27 de junho de 2020, divididos em duas categorias: dados demográficos (gênero, idade e cidade onde o paciente reside) e dados clínicos/laboratoriais (resultados de exames). Outras informações foram cedidas, como datas de entrada e saída do hospital e internações. Contudo, o desfecho clínico (alta hospitalar ou óbito) foi disponibilizado somente pelo Hospital Sírio-Libanês, o que justifica que os dados do presente projeto foram sobre análises do repositório apenas desse hospital.

O primeiro parâmetro de inclusão estabelecido foi de pacientes pertencentes ao hospital que informou o desfecho clínico e que testou positivo para SARS-CoV-2 através de um dos testes, como Transcrição Reversa seguida de Reação em Cadeia da Polimerase (RT-PCR), RT-PCR por anatomia patológica, ou sorologia (presença positiva da imunoglobulina IgM).

Para pareamento e comparação, como grupo controle foram selecionados em ordem alfanumérica e de forma aleatória, os primeiros pacientes que possuíam exames para os mesmos marcadores e receberam alta melhorada e/ou alta curada, até completar o número total encontrado no grupo óbito.

Foram então incluídos em cada grupo - alta hospitalar e óbito - 24 pacientes que testaram positivo para SARS-CoV2, totalizando 48 sujeitos, que apresentaram exames laboratoriais para Alanina Aminotransferase (ALT), Aspartato Aminotransferase (AST), glicemia, creatinina sérica (Cr sérica), taxa de filtração glomerular (TFG), bilirrubina total (BT), Velocidade de Hemossedimentação (VHS), proteína C reativa (PCR), eritrócitos, hemoglobina, leucócitos totais, diferencial de leucócitos (linfócitos, basófilos, monócitos, eosinófilos e neutrófilos), tempo de protrombina (TP), tempo de tromboplastina parcialmente ativada (TTPA) e dímero-D. Ambos os grupos possuíam dados dos exames citados em dois momentos: na internação e no desfecho (alta hospitalar ou óbito) para comparações distintas entre si.

Para a comparação entre os grupos, foram computadas as médias e desvios padrões de cada um dos testes analisados nos dois tipos de desfecho. No entanto, devido à grande variação nos desvios-padrões, foram também apresentados e comparados os valores mínimos e valores máximos encontrados em cada grupo, além da avaliação do número de pacientes que se encontravam acima ou abaixo dos valores de referência, assim como a piora do quadro pelas análises dessas determinações laboratoriais, considerando como piora o paciente que apresentou no desfecho alteração > 10\% do valor da internação. Vale ressaltar que para determinação de alterações foram utilizados os valores de referência estipulados pelo hospital que disponibilizou os dados para o repositório.

Após a compilação dos dados, foi realizada a análise estatística. Para a associação entre duas variáveis foi realizado o teste de Qui-Quadrado, enquanto para a análise de variância foi realizado o teste ANOVA de duas vias. Para verificar a distribuição normal entre os grupos, foi realizado o teste de Shapiro-wilk". 


\section{Resultados e discussão}

A análise descritiva realizada no presente estudo teve por finalidade avaliar a idade, sexo, os perfis bioquímicos, hematológico, inflamatório e de coagulação entre dois grupos, os que evoluíram para alta hospitalar e os que progrediram para o óbito, a fim de analisar possíveis características que pudessem diferenciá-los.

\section{Parâmetros Gerais}

No grupo que evoluiu para óbito a média de idade foi de $80 \pm 11$ anos, sendo 7 pacientes do sexo feminino e 17 do sexo masculino, com 23 destes residentes do Estado de São Paulo e 1 no Distrito Federal. Já no grupo que evoluiu para alta hospitalar, a média de idade foi de $65 \pm 15$ anos, sendo 10 pacientes do sexo feminino e 14 do sexo masculino, com 21 destes residentes do Estado de São Paulo, 1 no Pará, 1 em Minas Gerais e 1 residindo em outro país.

Observa-se assim que houve uma relação positiva entre a idade e maior risco de óbito em ambos os grupos ( $\mathrm{p}=0,008)$, uma vez que quanto mais avançada a idade, menor foi a chance de melhora/sobrevivência. Dos 24 pacientes analisados do grupo de óbito, 15 tinham entre 80 e 90 anos de idade, mostrando maior prevalência de indivíduos dessa faixa etária em relação às demais $(\mathrm{p}=0,000003)$.

De acordo com as características apresentadas, sugere-se que a idade avançada possa ser um fator contribuinte para um prognóstico ruim, conforme relatado por outros estudos (R. Chen et al., 2020; D. Wang et al., 2020; J. Chen et al., 2020; Wang et al., 2020b; Yang et al., 2020).

Outro fator levantado com o presente estudo, foi que o sexo masculino se destacou como o mais afetado, sendo coerente com os dados de D. Wang et al. (2020), que demonstraram em estudo com 138 pacientes, que 54,3\% pertenciam ao sexo masculino, assim como J. Chen et al. (2020), que descrevem em outra pesquisa que a $68 \%$ dos sujeitos acometidos pela infecção eram homens. Além disso, foi encontrado maior número de homens infectados do que mulheres, igualmente descrito em casos MERS-CoV e SARS-CoV por outros pesquisadores (Badawi \& Ryoo, 2016; Channappanavar et al., 2017). Jaillon et al. (2017) explicam que o menor índice de infecção no sexo feminino pode ter correlação com o fato de o cromossomo X e os hormônios sexuais exercerem funções significantes na imunidade adaptativa e inata. Esses estudos acabam sendo consistentes com os resultados do presente estudo. No entanto, as pesquisas realizadas por Djakpo et al. (2020), com 208 indivíduos, e a de Wang et al. (2020a), com 45 indivíduos, descrevem que não houve diferença no índice de infecção entre os sexos.

Desta forma, além da idade avançada ter contribuição para um pior desfecho, é possível que esses pacientes tivessem outras características envolvidas com a piora, como terem sido internados em condições mais críticas e apresentarem comorbidades pré-existente, o que não pode ser avaliado no presente estudo por essas informações não estarem disponíveis no banco de dados do repositório.

Já o tempo médio de internação entre os grupos não diferiu, tendo sido de 21 dias para os que obtiveram alta, e 22 dias para os que vieram a óbito, o que embora seja difere de do estudo de Desidério et al (2021) em que esse tempo foi maior para os que obtiveram sucesso terapêutico e alta, corrobora com o estudo de Teich et al. (2021) em que também não foi observada diferença nesse critério.

\section{Parâmetros bioquímicos}

Os dados laboratoriais bioquímicos dos indivíduos estão apresentados na Tabela 1, sendo expressos em média e desvio padrão dos resultados no momento da internação hospitalar e no desfecho, sendo alta ou óbito, dependendo do grupo. As tabelas também apresentam os valores mínimos e valores máximos encontrados para cada analito em cada grupo.

A Tabela 1 apresenta os resultados dos exames bioquímicos de AST, ALT, Bilirrubina total, TFG, creatinina sérica e glicemia dos dois grupos na íntegra. 
Tabela 1. Resultados dos exames bioquímicos de AST, ALT, Bilirrubina total, TFG, creatinina sérica e glicemia expressos em média e desvio padrão, valor mínimo e máximo encontrados nos grupos.

\begin{tabular}{cccccc}
\hline \multicolumn{2}{c}{ PARÂMETROS } & $\begin{array}{c}\text { ALTA } \\
\text { HOSPITALAR } \\
\text { MÉDIA } \pm \text { DP }\end{array}$ & $\begin{array}{c}\text { Mínimo / } \\
\text { Máximo }\end{array}$ & $\begin{array}{c}\text { ÓBITO } \\
\text { MÉDIA } \pm \\
\text { DP }\end{array}$ & $\begin{array}{c}\text { Mínimo / } \\
\text { Máximo }\end{array}$ \\
\hline internação & AST & $36 \pm 14$ & $14 / 78$ & $56 \pm 46$ & $9 / 201$ \\
Desfecho & AST & $39 \pm 27$ & $10 / 240$ & $830 \pm 2551$ & $14 / 10727$ \\
\hline internação & ALT & $33 \pm 17$ & $11 / 92$ & $41 \pm 39$ & $8 / 178$ \\
Desfecho & ALT & $54 \pm 44$ & $11 / 245$ & $350 \pm 1172$ & $9 / 5254$ \\
\hline internação & BT & $0,54 \pm 0,33$ & $0,06 / 3,8$ & $0,50 \pm 0,30$ & $0,18 / 1,31$ \\
Desfecho & BT & $0,42 \pm 0,17$ & $1,12 / 11$ & $2,15 \pm 4,42$ & $0,22 / 19,16$ \\
\hline internação & TFG & $62 \pm 18$ & $21 / 90$ & $53 \pm 25$ & $8 / 90$ \\
Desfecho & TFG & $74 \pm 14$ & $17 / 90$ & $39 \pm 29$ & $12 / 90$ \\
\hline Internação & CR sérica & $1,24 \pm 0,47$ & $0,69 / 2,69$ & $1,63 \pm 1,31$ & $0,49 / 5,74$ \\
\hline Desfecho & CR sérica & $1,05 \pm 0,34$ & $0,31 / 3,33$ & $2,29 \pm 1,20$ & $0,53 / 4,24$ \\
\hline internação & Glicemia & $125 \pm 34$ & $86 / 269$ & $134 \pm 53$ & $85 / 276$ \\
\hline Desfecho & Glicemia & $124 \pm 39$ & $87 / 269$ & $171 \pm 40$ & $17 / 658$ \\
\hline
\end{tabular}

ALT = Alanina Aminotransferase; AST = Aspartato Aminotransferase; TFG = Taxa de Filtração Glomerular; BT = Bilirrubina Total; $\mathrm{CR}$ sérica $=$ Creatinina sérica . As unidades de medida dos valores da bilirrubina total, creatinina sérica e glicemia são expressas como mg/dL. Já ALT e AST, são expressas em U/L, e a TFG em mL/min. Fonte: Autores (2022).

Na avaliação da AST, no grupo que evoluiu para alta hospitalar, 9 pacientes $(37,5 \%)$ apresentaram aumento desta proteína na internação, com apenas $5(20,83 \%)$ tendo apresentado aumento no desfecho e apenas 4 (16,66\%) com piora no quadro, enquanto no grupo que evoluiu para óbito, 12 (50\%) já apresentavam aumento desse parâmetro na internação, o que se manteve no desfecho, e 8 pacientes $(33,33 \%)$ evoluíram com piora nos resultados do exame. Após análise de multivariância foi verificado que não houve diferença estatística entre os grupos ( $\mathrm{p}=0,152)$, nem mesmo entre a internação e o desfecho para o grupo óbito $(\mathrm{p}=0,056)$ e grupo alta $(\mathrm{p}=0,994)$.

A análise de ALT resultou no grupo "alta hospitalar" em 5 (20,83\%) que apresentaram aumento no momento da internação, 9 (37,5\%) aumento no momento do desfecho, e 8 (33,33\%) com piora do quadro clínico e no grupo “óbito", 7 pacientes $(29,16 \%)$ com elevação da ALT na internação, 10 (41,66\%) com aumento no desfecho clínico, e 8 (33,33\%) com progressão de piora nos resultados do exame. Assim, como no AST, para ALT também não houve diferença estatística entre os grupos ( $\mathrm{p}=0,189)$, nem mesmo entre a internação e o desfecho para o grupo óbito ( $\mathrm{p}=0,094)$ e grupo alta $(\mathrm{p}=0,902)$.

No parâmetro de bilirrubina total, não houve diferença quando comparados os dois grupos $(\mathrm{p}=0,143)$ ou quando no grupo “alta hospitalar” se avaliou a comparação entre internação e desfecho ( $\mathrm{p}=0,833)$, uma vez que somente 1 (4,16\%) apresentou aumento na internação, que prevaleceu durante o desfecho e piora clínica. No entanto, no grupo "óbito" foi observada piora nesse analito quando avaliado os dois momentos $(\mathrm{p}=0,026)$, com 2 pacientes $(8,33 \%)$ com níveis elevados desse exame na internação, 5 (20,83\%) no desfecho, e 5 (20,83\%) com evolução no exame para piora do quadro clínico.

Desse modo, no que se refere a função hepática, para o grupo que evoluiu para o óbito, AST, ALT e bilirrubina total encontravam-se aumentados, cerca de 15 vezes (1482,14\%), 9 vezes (753,65\%) e 4,5 vezes (330\%), respectivamente, no 
momento de desfecho quando comparado à internação. Contudo, o grupo com desfecho de alta hospitalar, embora ainda apresentasse no desfecho aumento expressivo de ALT (63,63\%), AST aumentou apenas 8,3\% e a bilirrubina total reduziu em $22,2 \%$, demonstrando que a lesão ainda existia, mas que a função do órgão havia apresentado melhora. Ao equiparar o atual estudo com o de Y. Zhang et al. (2020), os pesquisadores demonstraram que 2 a 11\% dos pacientes infectados por SARS-CoV2 apresentavam alguma comorbidade hepática e que, os níveis de AST e ALT estavam alterados durante a progressão da doença em 14 a 53\% dos indivíduos. Enquanto isso, H. Shi et al. (2020) relataram que pacientes diagnosticados com COVID19 demonstravam na fase subclínica da doença, índices de anormalidades de AST menores quando comparado com diagnóstico após o início dos sintomas, mostrando desta forma que as lesões hepáticas se apresentam mais predominante em quadros mais graves da doença. Foi observado também por J. Chen et al. (2020), em estudo com 99 indivíduos, que 43 apresentavam alterações na função hepática em diferentes graus, estando a bilirrubina total aumentada em 18\% dos pacientes, junto com a elevação de AST e ALT, sendo 1 com lesão grave de função hepática, com AST de 1445 U/L e ALT de 7590 U/L. Lei et al. (2020) também descrevem que os níveis dos parâmetros de ALT, AST e bilirrubina total foram menores e com pouca diferença em pacientes que possuíam a doença em condições não graves e aumentavam quando o quadro clínico se tornava mais severo. Quando comparou os grupos de casos graves e não graves, foi verificada uma disparada diferença no nível de AST, com o estado mais severo da doença apresentando níveis bem significativos na admissão, mantendo-se mais elevados do que o estado leve. Ao analisar o ALT, foi observado aumento perceptível, porém não muito exorbitante quanto a AST na admissão dos sujeitos, tendo os valores normais rapidamente ultrapassado nos casos mais graves. Enquanto isso, os níveis de bilirrubina não apresentaram muita diferença entre os grupos. Os mesmos pesquisadores ainda dizem que a bilirrubina total foi importante para associar desfechos diferentes pela SARS-CoV-2. Sendo assim, os dados da avaliação da função hepática do presente estudo são consistentes com os resultados publicados na literatura e assim sugere que a AST possa se tornar um marcador para maior risco de mortalidade.

Já na análise da glicemia, esta foi maior no grupo que evoluiu para óbito ( $\mathrm{p}=0,0031)$, assim como na evolução entre internação e desfecho ( $\mathrm{p}=0,0041)$, o que não ocorreu no grupo "alta hospitalar" ( $\mathrm{p}=0,573)$. O grupo óbito teve aumento sob esse aspecto, uma vez que no grupo "alta hospitalar", 11 sujeitos $(45,83 \%)$ apresentaram níveis aumentados no momento de internação, 7 (29,16\%) no desfecho e apenas 4 (16,66\%) com progressiva piora, enquanto no grupo "óbito", 14 indivíduos $(58,33 \%)$ apresentavam níveis aumentados em sua internação, $13(54,16 \%)$ em seu desfecho, e $10(41,66 \%)$ piora no prognóstico avaliado por este exame.

A evidência de piora na glicemia entre pacientes em estado grave foi também referida por Wang et al. (2020), que mostraram que os níveis de glicose no sangue em jejum do grupo grave estavam mais aumentados do que o grupo moderado. Vale ressaltar que J. Chen et al. (2020) destacam a necessidade de monitorar a glicemia em pacientes infectados com COVID19, pois a associação viral e a hiperglicêmica aumentam as chances de um agravo no quadro clínico. Casqueiro et al. (2012) explicam que o estado hiperglicêmico do indivíduo aumenta a virulência dos patógenos, diminui a produção de interleucinas em resposta à infecção, além de reduzir a atividade fagocítica, o que pode explicar a associação entre aumento de glicemia e o agravamento do quadro.

$\mathrm{Na}$ avaliação da creatinina sérica, no grupo "alta hospitalar", 6 pacientes (25\%) apresentaram aumento acima dos níveis de referência do exame no momento da internação, 3 (12,5\%) no desfecho e 3 (12,5\%), piora clínica, enquanto no grupo "óbito" tenham 10 sujeitos (41,66\%) demonstraram aumento do exame na internação, 18 (75\%) no desfecho e 15 (62,5\%) que evoluíram para piora. A partir desses dados já foi possível prever o que a estatística confirmou, de que além de ter havido diferença estatística entre os grupos $(\mathrm{p}=0,002)$, houve piora no quadro quando avaliada a comparação da internação com o desfecho no grupo "óbito" ( $\mathrm{p}=0,002)$, o que não ocorreu no grupo dos que evoluíram para alta ( $\mathrm{p}=0,336)$. 
Quando avaliada a TFG, não houve diferença entre os grupos no desfecho ( $\mathrm{p}=0,276)$, embora na comparação da internação com o desfecho foi possível observar aumento deste parâmetro no grupo que evoluiu para alta e no que evoluiu para óbito ( $\mathrm{p}=0,019$ e $\mathrm{p}=0,0003$, respectivamente). Vale ressaltar que a piora foi maior no grupo "óbito", uma vez que 20 pacientes (83,33\%) apresentaram diminuição dessas taxas na internação, 19 (79,16\%) no desfecho, evoluindo 16 (66,66\%) para um quadro de piora, enquanto no grupo "alta hospitalar", 21 (87,5\%) apresentaram diminuição da TFG na internação, 15 (62,5\%) no desfecho, evoluindo apenas 2 indivíduos $(8,33 \%)$ para a piora.

Desse modo, no que se refere aos parâmetros de avaliação da função renal, no grupo de pacientes que evoluíram para óbito, ambos se encontraram alterados no desfecho, com diminuição dos exames de TFG (26,42\%) e elevação dos níveis de creatinina sérica (40,49\%), enquanto no grupo que recebeu alta hospitalar, foi observado o inverso, havendo elevação dos níveis de TFG $(19,35 \%)$ e diminuição da creatinina sérica $(15,32 \%)$. Tais resultados foram também observados por K. Wang et al.(2020), que avaliaram 296 pacientes, nos quais a creatinina sérica foi maior e a TFG significativamente menor no grupo de pacientes que vieram a óbito, quando comparado com os que receberam alta. Já Mikami et al. (2020) e Berenguer et al. (2020), também relataram diminuição do valor de TFG nos pacientes que evoluíram para óbito, tenho o primeiro estudo também relatado o aumento da creatinina nesses pacientes. Uma possível explicação para as alterações renais observadas de forma mais expressiva nos quadros de evolução para óbito foi descrita por Kellum et al. (2020), que declaram que devido ao SARS-Cov-2 se ligar ao ACE2, que possui uma expressão muito grande no rim, faz com que o órgão seja suscetível à infecção deste vírus, levando a lesões renais provenientes de sua adesão nas células e subsequente entrada. Vale ressaltar que as lesões renais seriam então provocadas pela elevação de citocinas pró-inflamatórias e trombose microvascular, conforme explicado por Gabarre et al. (2020). Com isso, pode-se considerar uma coerência dos dados encontrados no presente estudo com as informações existentes na literatura científica.

\section{Parâmetro inflamatório}

O processo inflamatório dos pacientes de ambos os grupos foi avaliado pela análise da Proteína C Reativa (PCR), estando os resultados apresentados na Tabela 2.

Tabela 2. Resultados de Proteína C Reativa expressos em média e desvio padrão, valor mínimo e máximo encontrados nos grupos.

\begin{tabular}{lccccc}
\hline PARÂMETROS & $\begin{array}{c}\text { ALTA } \\
\text { HOSPITALAR } \\
\text { MÉDIA } \pm \text { DP }\end{array}$ & $\begin{array}{c}\text { Mínima / } \\
\text { Máxima }\end{array}$ & $\begin{array}{c}\text { ÓBITO } \\
\text { MÉDIA } \pm \text { DP }\end{array}$ & $\begin{array}{c}\text { Mínima / } \\
\text { Máxima }\end{array}$ \\
\hline internação & PCR & $3,79 \pm 3,91$ & $0,03 / 19,13$ & $10 \pm 10$ & $0,05 / 36,96$ \\
Desfecho & PCR & $1,14 \pm 1,24$ & $0,03 / 7$ & $14 \pm 13$ & $0,55 / 36,64$ \\
\hline PCR $=$ Proteína C Reativa. As unidades de medida dos valores de PCR são expressas em mg/L. Fonte: Autores (2022).
\end{tabular}

Os níveis de PCR se apresentaram aumentados na internação em ambos os grupos, não havendo diferença quando comparados os grupos $(\mathrm{p}=0,653)$. No entanto, quando comparados os momentos de internação e desfecho, houve elevação apenas no grupo "óbito", o qual apresentou aumento acentuado no desfecho ( $\mathrm{p}=0,174)$, uma vez que dos 24 pacientes, 20 $(83,33 \%)$ apresentaram aumento na internação, 19 (79,16\%) no desfecho e 14 (58,33\%) com progressão para a piora do estado hospitalar. Já no grupo "alta hospitalar", $11(45,83 \%)$ mostraram aumento no momento de internação, que foi reduzido para 5 (20,83\%) no desfecho, com apenas 4 (16,66\%) evoluído para piora do quadro. 
Desse modo, a avaliação do parâmetro inflamatório constatou aumento de $40 \%$ nos níveis do exame laboratorial para o grupo que evolui à óbito e uma diminuição de $69,92 \%$ para aqueles que obtiveram alta hospitalar, quando comparada internação e desfecho. Esses dados corroboram com os descritos por Guan et al. (2020), que demonstraram que em diversas províncias da China, cerca de 60,7\% dos pacientes apresentavam aumento de PCR, e que esses valores eram mais elevados em pacientes em estado mais crítico. Wu et al. (2020) relacionaram esse aumento com características ruins da doença, como uma progressão para SDRA. R. Chen et al. (2020) e J. Chen et al. (2020), relatam em seus estudos o aumento da PCR em mais da metade dos indivíduos estudados com COVID-19 (73\%), enquanto Berenguer et al. (2020) encontraram elevação da PCR em um número ainda maior de pacientes com COVID-19 (91,9\%). Djakpo et al. (2020) descreveram em seu estudo retrospectivo realizado com os dados de 208 indivíduos, que a PCR aumentava devido a uma resposta do corpo contra o processo infeccioso gerado pela COVID-19, assim como Landry et al. (2020), que acrescentaram ainda que a PCR também pode estar aumentada pelos danos provocados aos tecidos, sendo então esse aumento conhecido, no decorrer de processos infecciosos, e processos inflamatórios, como descrito por outros estudiosos (Hajek et al., 2020).

O mecanismo que explica esse aumento da proteína C reativa nos pacientes COVID-19 se refere ao fato de que, após a entrada do vírus nos pneumócitos via receptor da ACE2, ocorre uma resposta inflamatória sistêmica, criando uma disfunção imune com hiperatividade dos linfócitos T e liberação de pró citocinas inflamatórias mencionadas (Jin et al, 2020; Yuki et al, 2020).

\section{Parâmetros de coagulação}

A avaliação do perfil de coagulação foi realizada pelas análises dos testes de TP, TTPA e dímero-D, estando os resultados desses analitos apresentados na tabela 3 .

Tabela 3. Resultados de TP, TTPA e dímero-D expressos em média e desvio padrão, valor mínimo e máximo encontrados nos grupos.

\begin{tabular}{|c|c|c|c|c|c|}
\hline \multicolumn{2}{|c|}{ PARÂMETROS } & $\begin{array}{c}\text { ALTA } \\
\text { HOSPITALAR } \\
(\text { MÉDIA } \pm \text { DP) }\end{array}$ & $\begin{array}{l}\text { Mínima / } \\
\text { Máxima }\end{array}$ & $\begin{array}{c}\text { ÓBITO } \\
\text { (MÉDIA } \pm \text { DP) }\end{array}$ & $\begin{array}{l}\text { Mínima / } \\
\text { Máxima }\end{array}$ \\
\hline internação & TP & $13,1 \pm 1,9$ & $11 / 16,9$ & $12,9 \pm 1,4$ & $10,6 / 15$ \\
\hline Desfecho & TP & $12,1 \pm 1,0$ & $11,1 / 14$ & $18,6 \pm 19,8$ & $10,7 / 104,1$ \\
\hline internação & TTPA & $31,7 \pm 4,8$ & $24,3 / 38,7$ & $36,1 \pm 20,9$ & $20,2 / 129,3$ \\
\hline Desfecho & TTPA & $29,6 \pm 2,5$ & $25,3 / 32,7$ & $45,9 \pm 24,9$ & $23,3 / 126,8$ \\
\hline internação & Dímero D & $1371 \pm 1551$ & $214 / 5953$ & $1683,82 \pm 2061,09$ & $215 / 10000$ \\
\hline Desfecho & Dímero D & $956 \pm 1140$ & $214 / 4792$ & $5804 \pm 8494$ & $553 / 33117$ \\
\hline
\end{tabular}

Na avaliação de TP, no grupo “óbito", 11 (45,83\%) pacientes apresentaram aumento nesse parâmetro na internação, $13(54,16 \%)$ no momento de desfecho, e $12(50 \%)$ em piora, enquanto no grupo alta não houve piora de nenhum paciente e apenas $7(29,16 \%)$ obtiveram aumento desse parâmetro na internação e $3(12,5 \%)$ no momento do desfecho. Quando realizada 
a comparação entre os grupos, esta mostrou não haver diferença $(\mathrm{p}=0,408)$, também não tendo havido na comparação entre a internação e desfecho em ambos os grupos, alta e óbito ( $\mathrm{p}=0,717$ e p= 0,0976, respectivamente).

Já na avaliação do TTPA, também não houve diferença entre os grupos $(\mathrm{p}=0,304)$, mas, quando comparado internação e desfecho, foi observado aumento no grupo "óbito" ( $\mathrm{p}=0,048)$, com 8 pacientes $(33,33 \%)$ apresentando elevação na internação, 12 (50\%) no momento de desfecho, e 12 (50\%) com evolução de pior, enquanto no grupo "alta hospitalar", 6 indivíduos (25\%) tiveram elevação na internação, nenhum no desfecho e apenas $1(4,16 \%)$ com piora.

Por fim, a análise do dímero-D mostrou aumento desse parâmetro no grupo "óbito" em relação ao grupo "alta" ( $\mathrm{p}=0,047)$, além de aumento pronunciado no desfecho óbito em comparação com a internação ( $\mathrm{p}=0,003)$, uma vez que nesse grupo 20 (83,33\%) estavam com elevações superiores à referência dos valores do parâmetro no momento de internação, 21 $(87,5 \%)$ no ato do desfecho e 17 (70,83\%) com progressão de piora. Já o grupo "alta hospitalar" não apresentou diferença entre os momentos de análise, com 18 (75\%) apresentando valores superiores aos definidos como referência na internação, 11 $(45,83 \%)$ no período de desfecho e apenas 4 (16,66\%) com piora nesse parâmetro.

Desse modo, ao avaliar em conjunto esses dados de parâmetros de coagulação, verificou-se piora no grupo "óbito", visto pelo aumento dos níveis de TP (44,19\%), TTPA (27,15\%) e dímero-D (244,66\%), no desfecho em comparação com a internação. Já o grupo "alta hospitalar" mostrou níveis mais baixos dos três parâmetros no desfecho, tendo havido redução TP (7,63\%), TTPA (6,62\%) e dímero-D (30,27\%). Segundo Deng et al. (2020), distúrbios na coagulação são frequentes nos pacientes diagnosticados com SARS-CoV-2, principalmente nos casos graves.

Han et al. (2020) avaliaram os parâmetros de coagulação de indivíduos infectados por coronavírus e descreveram um aumento evidente de dímero D em comparação com sujeitos saudáveis. Chen et al. (2020c) também demonstrou em estudo realizado com 99 pacientes com COVID-19, aumento no dímero D em 36\% dos indivíduos.

Vários estudos também correlacionaram o aumento do dímero-D com a gravidade da doença. Um deles foi o realizado com 560 pacientes, de Guan et al. (2020), que demonstrou que 46,4\% dos indivíduos infectados pela doença apresentavam aumento nos níveis de dímero D e que esse era mais expressivos em quadros mais críticos da doença. Snijjders et al. (2020) também correlacionaram valores do dímero D e gravidade, incluindo a ocorrência de quadros de pneumonia. Já Huang et al. (2020) descreveram que os níveis de dímero D e TP apresentavam-se elevados no momento da admissão entre os indivíduos que necessitaram de atendimento na UTI, obtendo a mediana do dímero D de 2,4 mg/L para pacientes com suporte na UTI e de 0,5 mg/L para os que não necessitaram de suporte na UTI, e TP médio de 12,2s para UTI e 10,7s. Outro estudo que corrobora com esses resultados foi o realizado por D. Wang et al. (2020), que relata que pacientes admitidos à UTI demonstravam dímero D expressivamente maiores em comparação aos casos menos graves.

Outros três artigos correlacionaram esse aumento diretamente ao maior risco de óbito, como é o caso do estudo de Zhou et al., (2020), Tang et al. (2020), em que também é evidenciado que resultados de TP e TTPA prolongados estão associados a pacientes que vieram à óbito, e o de Wu et al. (2020), que relatou que dos 201 pacientes com diagnostico de pneumonia desenvolvida pela COVID-19, a elevação de TP e dímero-D estava correlacionada a risco aumentado no desenvolvimento de SDRA e óbito.

Essa correlação de gravidade e aumento dos exames de análise de coagulação trouxeram a discussão de muitas possíveis causas para essa ocorrência. S. Shi et al. (2020), relatam que os indivíduos que apresentaram lesão cardíaca na infecção por SARS-CoV-2 encontram-se mais predispostos a disfunção de coagulação, quando comparado com pacientes sem comprometimento cardíaco. O mesmo foi discutido por Guo et al. (2020), que confirmam que indivíduos com aumento nos níveis de troponina $\mathrm{T}$, possivelmente apresentam com mais frequência aumento de TP, TTPA e dímero D. Um outro estudo realizado, por Wu et al. (2020), relatou que dos 201 pacientes com diagnostico de pneumonia desenvolvida pela COVID-19, a elevação de TP e dímero-D está correlacionada a um risco aumentado no desenvolvimento de SDRA e de evoluir para óbito. 
No entanto, o mecanismo pelo qual pacientes críticos com COVID-19 desenvolvem quadros de hipercoagulabilidade maior frequência do que a população geral ainda permanece incerto, assim como se esse aumento da coagulação é induzido pelo grau de viremia e pelo próprio vírus, ou se isso é simplesmente uma resposta à inflamação sistêmica profunda no paciente crítico, que são conhecidos fatores de risco para o aumento de coagulação, como no caso de TEV (Chen et al, 2020; Zhang et al, 2020). Essa associação entre o dímero-d elevado e o desenvolvimento de quadros trombóticos é então provavelmente representativa tanto do grau de inflamação sistêmica em pacientes criticamente doentes com COVID-19, quanto da ativação inadequada da cascata de coagulação; no entanto, o grau em que cada um desses componentes contribui para o desenvolvimento de TEV ainda não está claro.

Diante do aqui exposto, é essencial a avaliação da coagulação para prognóstico de pacientes com COVID-19.

\section{Parâmetros hematológicos}

Os dados hematológicos compostos pelos resultados de hemoglobina, eritrócitos, plaquetas, leucócitos totais, monócitos, basófilos, neutrófilos, linfócitos e eosinófilos estão presentes na Tabela 4. 
Tabela 4. Resultados de expressos hemoglobina, eritrócitos, plaquetas, leucócitos totais, monócitos, basófilos, neutrófilos, linfócitos e eosinófilos em média e desvio padrão, valor mínimo e máximo encontrados nos grupos.

\begin{tabular}{|c|c|c|c|c|c|}
\hline \multicolumn{2}{|c|}{ PARÂMETROS } & $\begin{array}{c}\text { ALTA } \\
\text { HOSPITALAR } \\
\text { MÉDIA } \pm \text { DP }\end{array}$ & $\begin{array}{l}\text { Mínima / } \\
\text { Máxima }\end{array}$ & $\begin{array}{c}\text { ÓBITO MÉDIA } \\
\text { 土 DP }\end{array}$ & $\begin{array}{l}\text { Mínima / } \\
\text { Máxima }\end{array}$ \\
\hline Internação & Hemoglobina & $13,4 \pm 1,6$ & $9,4 / 16,5$ & $12,7 \pm 3,0$ & $7,8 / 21,3$ \\
\hline Desfecho & Hemoglobina & $12,3 \pm 1,9$ & $8 / 15,5$ & $10,3 \pm 2,4$ & $6,6 / 15,8$ \\
\hline Internação & Eritrócitos & $4,53 \pm 0,63$ & $6,12 / 2,97$ & $4,28 \pm 0,86$ & $2,9 / 6,88$ \\
\hline Desfecho & Eritrócitos & $4,15 \pm 0,79$ & $2,49 / 5,89$ & $3,51 \pm 0,74$ & $2,39 / 4,97$ \\
\hline Internação & Hematócrito & $40,3 \pm 4,3$ & $29,4 / 52,9$ & $38,8 \pm 8,2$ & $25,1 / 62,1$ \\
\hline Desfecho & Hematócrito & $37,2 \pm 5,1$ & $25,9 / 46,7$ & $32,1 \pm 7,2$ & $20,2 / 48,2$ \\
\hline Internação & Plaquetas & $199458 \pm 72955$ & $\begin{array}{l}64000 / \\
378000\end{array}$ & $170542 \pm 63490$ & $31000 / 270000$ \\
\hline Desfecho & Plaquetas & $262292 \pm 104820$ & $\begin{array}{c}108000 / \\
510000\end{array}$ & $195375 \pm 173515$ & $16000 / 614000$ \\
\hline Internação & Leucócitos Totais & $6190 \pm 2314$ & $2230 / 16160$ & $8646 \pm 5996$ & $2590 / 26160$ \\
\hline Desfecho & Leucócitos Totais & $6743 \pm 1755$ & $2750 / 10350$ & $14733 \pm 10199$ & $1360 / 51920$ \\
\hline Internação & Linfócitos & $1284 \pm 667$ & $280 / 2830$ & $989 \pm 555$ & $380 / 2590$ \\
\hline Desfecho & Linfócitos & $1862 \pm 1166$ & $670 / 6490$ & $750 \pm 529$ & $210 / 2220$ \\
\hline Internação & Monócitos & $546 \pm 287$ & $90 / 1390$ & $608 \pm 401$ & $150 / 1960$ \\
\hline Desfecho & Monócitos & $698 \pm 308$ & $100 / 1690$ & $894 \pm 699$ & $40 / 2580$ \\
\hline Internação & Neutrófilos & $4265 \pm 2697$ & $1190 / 12280$ & $7070 \pm 6010$ & $1320 / 24300$ \\
\hline Desfecho & Neutrófilos & $4115 \pm 1745$ & $1300 / 7220$ & $12860 \pm 10066$ & $80 / 50010$ \\
\hline Internação & Basófilos & $20 \pm 13$ & $0 / 50$ & $29 \pm 33$ & $0 / 170$ \\
\hline Desfecho & Basófilos & $42 \pm 22$ & $0 / 90$ & $56 \pm 125$ & $0 / 620$ \\
\hline Internação & Eosinófilos & $71 \pm 99$ & $0 / 410$ & $40 \pm 62$ & $0 / 270$ \\
\hline Desfecho & Eosinófilos & $194 \pm 141$ & $10 / 480$ & $82 \pm 193$ & $0 / 700$ \\
\hline
\end{tabular}

Todas as unidades de medida dos valores do diferencial de leucócitos são expressas em $\mathrm{mm}^{3}$, assim como leucócitos totais, plaquetas e eritrócitos. A hemoglobina é expressa em g/dL e hematócrito como \%. Fonte: Autores (2022).

Ao analisar os valores de hemoglobina pode-se observar que ocorreu diferença estatística $(p=0,000071)$ entre os grupos, no qual o grupo que evolui para óbito apresentou valores menores dos que os do grupo que evoluiu para alta. Além disso, no grupo que evoluiu para óbito, este parâmetro diminuiu ainda mais no desfecho, em comparação com a internação ( $p=0,00009)$. Em contrapartida, o grupo que teve o desfecho alta, não apresentou diferença estatística em relação ao momento 
inicial e final $(\mathrm{p}=0,066)$. Esses dados são reflexo dos pacientes totais do grupo que evoluíram para alta hospitalar, em que 7 (29,16\%) obtiveram diminuição no momento da internação e 11 (45,83\%) diminuíram no momento do desfecho, que se manteve na piora do quadro clínico, enquanto no grupo evoluído para óbito houve $12(50 \%)$ com valores abaixo na internação, 19 (79,16\%) diminuídos no desfecho clínico e 16 (66,66\%) com progressão de piora.

$\mathrm{Na}$ análise dos eritrócitos foi possível observar que houve diferença entre os grupos ( $\mathrm{p}=0,000007)$ sendo que, o grupo que teve o desfecho óbito teve diminuição destes valores em comparação com os de alta hospitalar. Ao fazer a análise entre o momento inicial e final do mesmo grupo, percebeu-se que eles tiveram diminuição nos valores de eritrócitos ( $\mathrm{p}=0,000015)$. $\mathrm{O}$ grupo com o desfecho clínico alta também apresentou diferença em relação ao momento inicial e final $(\mathrm{p}=0,02)$, tendo os valores de eritrócitos diminuídos em relação ao momento da internação.

O exame de hematócrito mostra que houve diferença entre os grupos ( $\mathrm{p}=0,000218)$, com o grupo que foi a óbito com menor valor no desfecho, em relação à internação $(p=0,0003)$. Todavia, o grupo com desfecho alta não apresentou diferença na análise entre os dois momentos ( $\mathrm{p}=0,079)$.

$\mathrm{Na}$ avaliação das plaquetas houve diferença entre os grupos $(\mathrm{p}=0,026)$, uma vez que o grupo que evoluiu para óbito apresentou valor inferior em relação ao grupo óbito. Ocorreu também diferença na análise entre o momento de internação e desfecho para o grupo alta $(\mathrm{p}=0,025)$, tendo havido aumento em seus valores de plaquetas no desfecho. $\mathrm{O}$ grupo que teve o desfecho óbito não apresentou diferença entre os dois momentos de análise ( $\mathrm{p}=0,363)$.

Para os leucócitos totais também houve diferença entre os grupos $(\mathrm{p}=0,004)$, no qual o grupo que teve o desfecho óbito apresentou valor mais elevado. Comparando o momento da internação e desfecho, o grupo óbito demonstrou ocorrer aumento dos valores ( $\mathrm{p}=0,000257)$, enquanto o mesmo não ocorreu no grupo que teve o desfecho alta $(\mathrm{p}=0,721)$.

Ao avaliar a contagem de linfócitos, não foi evidenciada diferença entre os grupos $(\mathrm{p}=0,180)$. No entanto, na análise de evolução, no grupo que evoluiu para alta hospitalar observou-se aumento nos valores de linfócitos no desfecho $(\mathrm{p}=0,002)$, o que não foi observado no grupo que evoluiu para óbito $(\mathrm{p}=0,181)$.

$\mathrm{Na}$ análise da contagem de monócitos, esta foi maior no grupo "óbito" em relação ao "alta hospitalar" $(\mathrm{p}=0,005)$. Além disso, na análise entre os dois momentos, no grupo que evoluiu para óbito houve aumento de monócitos no desfecho em relação à internação $(\mathrm{p}=0,009)$, o que não ocorreu no grupo de alta hospitalar $(\mathrm{p}=0,167)$. Essas análises confirmam o observado em porcentagem de pacientes com alterações nesse parâmetro, tendo sido no grupo "óbito" de 5 (20,83\%) com elevações nos valores do parâmetro no momento da internação, 6 (25\%) no ato do desfecho e 4 (16,66\%) com progressão de piora, enquanto no grupo "alta hospitalar" apenas 2 mostraram-se aumentados na internação, 4 no período de desfecho, além de 5 pacientes que avançaram para uma piora.

Na contagem de neutrófilos, no grupo que evoluiu para óbito, 8 pacientes $(33,33 \%)$ apresentaram níveis elevados dessa célula no momento da internação, 17 (70,83\%) no desfecho e 15 pacientes $(62,5 \%)$ com evolução de piora, enquanto no grupo que evoluiu para alta, apenas $3(12,5)$ apresentavam aumento na internação, $1(4,16 \%)$ no desfecho e $1(4,16 \%)$, piora. Desse modo, houve diferença entre os grupos $(\mathrm{p}=0,019)$ sendo que o grupo que foi a óbito demonstrou aumento na contagem de neutrófilos, além de diferença entre os momentos de internação e desfecho no grupo "óbito" ( $p=0,001)$, o que não se repetiu no grupo "alta hospitalar" $(\mathrm{p}=0,976)$.

Observando-se que a contagem de eosinófilos, houve diferença entre os grupos $(\mathrm{p}=0,002)$, visto que o grupo que evoluiu para alta demonstrou aumento nestes valores $(\mathrm{p}=0,002)$, tendo ocorrido também diferença neste mesmo grupo, referente ao momento da internação e alta $(\mathrm{p}=0,002)$, o que não foi observado no grupo que evoluiu para óbito ( $\mathrm{p}=0,202)$.

Por fim, na avaliação dos basófilos, não houve diferença desse parâmetro entre os grupos ( $\mathrm{p}=0,58)$, nem mesmo na avaliação dos desfechos de alta e óbito ( $\mathrm{p}=0,273$ e p=0,108, respectivamente). 
Desse modo, na avaliação dos parâmetros hematológicos, pode-se verificar que os dados do presente estudo corroboram com muitos dos apresentados no estudo de Wang et al. (2020a), no qual o grupo mais grave de COVID-19 também apresentou maiores valores de leucócitos totais e menores de plaquetas, eritrócitos, hemoglobina e hematócrito, quando comparado com o grupo que apresentou doença moderada.

Com as análises de hemoglobina, eritrócitos e hematócrito, que avaliam a ocorrência ou não de quadros anêmicos, foi possível então verificar que todos estavam reduzidos no desfecho óbito, podendo estar associado com maior incidência e gravidade de anemia nesse grupo. Vale ressaltar que já é sabido que a anemia está associada a doença grave na COVID-19 (Tao et al, 2020). A anemia comumente agrava a gravidade das doenças respiratórias, e tem sido documentado que doenças respiratórias combinadas com anemia estão associadas a desfechos ruins e aumento da mortalidade (Reade et al, 2010). Até agora, poucas pesquisas observaram as características clínicas de pacientes com COVID-19 com anemia, bem como a correlação direta entre anemia e gravidade da doença em pacientes com COVID-19, deixando ainda não esclarecida completamente esta correlação. No entanto, uma vez que é consenso que anemia diminuiu o fornecimento de oxigênio aos tecidos, é plausível especular que pacientes com COVID-19 sejam mais suscetíveis à doença grave devido à pior função pulmonar e oxigenação dos tecidos (Tao et al, 2020; Djakpo et al., 2020; Wang et al., 2020a), podendo evoluir para óbito, como observado no presente estudo.

Além disso, na análise das plaquetas, foi observado que esta foi menor no grupo "óbito", assim como tenha aumentado no grupo "alta" durante a melhora do quadro da internação ao desfecho. Uma possível explicação para a baixa de plaquetas e eritrócitos, esta última acarretando baixa também de hemoglobina e hematócrito, é o fato do coronavírus conseguir infectar e reduzir a produção das células da medula óssea, interferindo na síntese das mesmas (Djakpo et al., 2020; Wang et al., 2020a). Denwang et al. (2020) ainda discute a possibilidade das plaquetas serem destruídas perifericamente pelo sistema imunológico, gerando anticorpos para destruir os próprios trombócitos e, consequentemente, gerar problemas de coagulação, como já visto em outras infecções virais, como no HIV 1.

Já nas análises dos leucócitos, os valores totais, assim como contagem de neutrófilos, eosinófilos e monócitos foram maiores no grupo "'obito", havendo também piora desses valores com o desfecho, mostrando uma resposta inflamatória exacerbada, muito associada com os quadros de piora da COVID-19, uma vez que neutrófilos e monócitos são considerados biomarcadores de inflamação sistêmica.

Por outro lado, foram menores os valores de linfócitos nesse grupo. Esses dados corroboram com os encontrados por Danwang et al. (2020), que enfatizam como principais alterações a diminuição de plaquetas e linfócitos em casos mais severos, as quais estão fortemente ligadas ao agravo da doença, assim como com os de Qin et al. (2020), que descrevem que os pacientes COVID-19 tiveram diminuição de linfócitos e aumento de leucócitos totais, tendo o aumento de neutrófilos sido maior nos pacientes em estágio mais severo. Este último estudo ainda discute que os níveis altos de citocinas pró-inflamatórias e quimiocinas encontrados nos pacientes mais graves pode explicar a correlação das células de defesa do sistema imune com as lesões pulmonares causada pelo vírus, que podem aumentar a relação de neutrófilo e linfócito no soro do indivíduo que possuiu um desfecho adverso.

Danwang et al. (2020) também enfatizaram que esta resposta imune marcada por uma linfopenia profunda parece ser uma complicação tardia que ocorre após liberação maciça precoce de citocinas durante o curso da lesão pulmonar na COVID19, podendo ser explicada por mecanismos diretos e/ou indiretos. O direto pode estar relacionado à citotoxicidade do 2019nCoV, sustentada pela replicação viral ativa dentro do pool de linfócitos infectados ( $\mathrm{Li}$ et al, 2020), embora alguns acreditem que a enzima conversora de angiotensina 2 (ACE2) não é expressa em linfócitos B ou T circulantes (Hamming et al, 2004). Já o indireto por estar relacionado aos macrófagos alveolares que podem promover a entrada viral através da apresentação de antígenos aos linfócitos ( $\mathrm{Li}$ et al, 2020), à enorme liberação de citocinas que podem induzir a apoptose celular (Li et al, 2020) 
ou aos altos níveis de glicocorticoides induzidos pelo vírus que pode levar à ativação de linfócitos e à alteração da proliferação (Shi et al, 2020).

\section{Conclusão}

Em vista dos dados apresentados, conclui-se que o tempo de internação não influenciou no desfecho clínico dos pacientes em alta ou óbito, enquanto a idade mais avançada e o sexo foram fatores contribuintes para o agravo do quadro clínico dos pacientes infectados pela COVID-19.

$\mathrm{Na}$ análise dos perfis bioquímicos, inflamatório e de coagulação, dímero-D e glicemia foram mais altas no grupo óbito, demonstrando uma relação da infecção com a coagulação sanguínea e a hiperglicemia. Já quando comparado o momento de internação e o desfecho do paciente, apenas a TFG apresentou piora em ambos os grupos, enquanto TTPA, bilirrubina total, creatinina sérica, glicemia, dímero-D e PCR aumentaram apenas no desfecho dos pacientes que vieram à óbito, tendo esse último reduzido no grupo "alta hospitalar".

$\mathrm{Na}$ análise do perfil hematológico, houve menores índices de hemoglobina, eritrócitos e hematócrito, compatível com maior risco de anemia, assim como aumento de leucócitos, neutrófilos e basófilos, indicadores de resposta inflamatória exacerbada, no grupo de pacientes que evoluiu para óbito, assim como visto em diversos outros relatos de estudos. Além disso, também foi observado nesse grupo, redução de plaquetas e linfócitos, também em concordância com a maioria dos estudos.

Desse modo, as variações encontradas nos parâmetros bioquímicos, inflamatório, de coagulação e hematológicos refletem as constantes alterações desses parâmetros ocorridas nos pacientes COVID-19, sendo mais pronunciados nos pacientes que evoluíram para óbito, uma vez que os pacientes desse grupo apresentaram mais frequentemente alterações desde o processo de internação, apresentando um processo de prognóstico ruim até o momento do desfecho.

No entanto, em decorrência da doença causada pelo SARS-CoV-2 ser recente, e assim, consequentemente as suas complicações clínicas, novos estudos com amostragens maiores são ainda necessários para melhor esclarecimento das alterações bioquímicas e hematológicas causadas pela COVID-19.

\section{Referências}

Alves, B. O. O.-M. Novo Coronavírus (COVID-19): informações básicas | Biblioteca Virtual em Saúde MS. https://bvsms.saude.gov.br/novo-coronavirusCOVID-19-informacoes-basicas/

Ashour, H. M., Elkhatib, W. F., Rahman, M. M., \& Elshabrawy, H. A. (2020). Insights into the Recent 2019 Novel Coronavirus (SARS-CoV-2) in Light of Past Human Coronavirus Outbreaks. Pathogens, 9(3), 186. doi:10.3390/pathogens9030186

Badawi, A., \& Ryoo, S. G. (2016). Prevalence of comorbidities in the Middle East respiratory syndrome coronavirus (MERS-CoV): a systematic review and meta-analysis. International journal of infectious diseases. IJID: official publication of the International Society for Infectious Diseases, 49, $129-133$. doi:https://doi.org/10.1016/j.ijid.2016.06.015

Baloch, S., Baloch, M. A., Zheng, T., \& Pei, X. (2020). The Coronavirus Disease 2019 (COVID-19) Pandemic. The Tohoku journal of experimental medicine, 250(4), 271-278. doi:https://doi.org/10.1620/tjem.250.271

Berenguer, J., Ryan, P., Rodríguez-Baño, J., Jarrín, I., Carratalà, J., Pachón, ...Arriba, J. R. (2020). Characteristics and predictors of death among 4035 consecutively hospitalized patients with COVID-19 in Spain. Clinical microbiology and infection: the official publication of the European Society of Clinical Microbiology and Infectious Diseases, 26(11), 1525-1536. https://doi.org/10.1016/j.cmi.2020.07.024

Bourgonje, A. R., Abdulle, A. E., Timens, W., Hillebrands, J. L., Navis, G. J., Gordijn, S. J....Van Goor, H. (2020). Angiotensin-converting enzyme 2 (ACE2), SARS-CoV-2 and the pathophysiology of coronavirus disease 2019 (COVID-19). The Journal of pathology, 251(3), 228-248. https://doi.org/10.1002/path.5471

Callender, L. A., Curran, M., Bates, S. M., Mairesse, M., Weigandt, J., \& Betts, C. J. (2020). The Impact of Pre-existing Comorbidities and Therapeutic Interventions on COVID-19. Frontiers in immunology, 11, 1991. https://doi.org/10.3389/fimmu.2020.01991

Casqueiro, J., Casqueiro, J., \& Alves, C. (2012). Infections in patients with diabetes mellitus: A review of pathogenesis. Indian journal of endocrinology and metabolism, 16 Suppl 1(Supp11), S27-S36. doi:https://doi.org/10.4103/2230-8210.94253

Channappanavar, R., Fett, C., Mack, M., Ten Eyck, P. P., Meyerholz, D. K., \& Perlman, S. (2017). Sex-Based Differences in Susceptibility to Severe Acute Respiratory Syndrome Coronavirus Infection. Journal of immunology (Baltimore, Md: 1950), 198(10), 4046-4053. 
doi:https://doi.org/10.4049/jimmunol.1601896

Chen, R., Sang, L., Jiang, M., et al. Longitudinal hematologic and immunologic variations associated with the progression of COVID-19 patients in China. J Allergy Clin Immunol. 2020;146(1):89-100. 10.1016/j.jaci.2020.05.003

Chen, J., Qi, T., Liu, L., Ling, Y., Qian, Z., Li, T., Li, F., \& Lu, H. (2020). Clinical progression of patients with COVID-19 in Shanghai, China. The Journal of infection, 80(5), e1-e6. doi:https://doi.org/10.1016/j.jinf.2020.03.004

Chen, J., Wu, C., Wang, X., Yu, J., \& Sun, Z. (2020). The Impact of COVID-19 on Blood Glucose: A Systematic Review and Meta-Analysis. Frontiers in endocrinology, 11, 574541. https://doi.org/10.3389/fendo.2020.574541

Chen, N., Zhou, M., Dong, X., Qu, J., Gong, F., Han, Y., \& Zhang, L. (2020). Epidemiological and clinical characteristics of 99 cases of 2019 novel coronavirus pneumonia in Wuhan, China: a descriptive study. The Lancet, 395(10223). https://doi.org/10.1016/s0140-6736(20)30211-7

Danwang, C., Endomba, F. T., Nkeck, J. R., Wouna, D., Robert, A., \& Noubiap, J. J. (2020). A meta-analysis of potential biomarkers associated with severity of coronavirus disease 2019 (COVID-19). Biomarker research, 8, 37. doi:https://doi.org/10.1186/s40364-020-00217-0

Deng, Y., Liu, W., Liu, K., Fang, Y. Y., Shang, J., Zhou, L., \& Liu, H. G. (2020). Clinical characteristics of fatal and recovered cases of coronavirus disease 2019 in Wuhan, China: a retrospective study. Chinese medical journal, 133(11), 1261-1267. https://doi.org/10.1097/CM9.0000000000000824

Desiderio, V. L., Fabio, V., Cárnio, E. C., Silva, H. B. \& Marchi-Alves, L. M. (2021). Variáveis associadas ao desfecho clínico de pacientes hospitalizados por COVID-19. Rev Med (São Paulo), 100(5), 431-41. doi:http://dx.doi.org/10.11606/issn.1679-9836.v100i5p431-441

Djakpo, D. K., Wang, Z., Zhang, R., Chen, X., Chen, P., \& Antoine, M. (2020). Blood routine test in mild and common 2019 coronavirus (COVID-19) patients. Bioscience reports, 40(8), BSR20200817. doi:https://doi.org/10.1042/BSR20200817

Fapesp. COVID-19 Data Sharing/BR. Disponível em: https://repositoriodatasharingfapesp.uspdigital.usp.br/

Gabarre, P., Dumas, G., Dupont, T., Darmon, M., Azoulay, E., \& Zafrani, L. (2020). Acute kidney injury in critically ill patients with COVID-19. Intensive care medicine, 46(7), 1339-1348. doi:https://doi.org/10.1007/s00134-020-06153-9

Ge, H., Wang, X., Yuan, X., Xiao, G., Wang, C., Deng, T., Yuan, Q. \& Xiao, X. (2020). The epidemiology and clinical information about COVID19. European journal of clinical microbiology \& infectious disease: official publication of the European Society of Clinical Microbiology, 39(6), 1011-1019. doi:https://doi.org/10.1007/s10096-020-03874-z

Gralinski, L. E., \& Menachery, V. D. (2020). Return of the Coronavirus: 2019-nCoV. Viruses, 12(2), 135. https://doi.org/10.3390/v12020135

Guan, W., Ni, Z., Hu, Y., Liang, W., Ou, C., He, J...Li, S. (2020). Clinical Characteristics of Coronavirus Disease 2019 in China. New England Journal of Medicine, 382(18). https://doi.org/10.1056/nejmoa2002032

Guo, T., Fan, Y., Chen, M., Wu, X., Zhang, L., He, T., \& Lu, Z. (2020). Cardiovascular Implications of Fatal Outcomes of Patients With Coronavirus Disease 2019 (COVID-19). JAMA cardiology, 5(7), 811-818. https://doi.org/10.1001/jamacardio.2020.1017

Hajek, V., Pasquet, F., Karkowski, L., Lachenal, F., Gerôme, P., \& Pavic, M. (2011). Profil étiologique et pronostique des valeurs extrêmes ( $\geq 500$ mg/L) de protéine C-réactive: étude rétrospective de 168 valeurs chez 113 patients. La Revue de Médecine Interne, 32(11), 663-668. doi:https://doi.org/10.1016/j.revmed.2011.04.001

Han, H., Yang, L., Liu, R., Liu, F., Wu, K. L., Li, J., Liu, X. H., \& Zhu, C. L. (2020). Prominent changes in blood coagulation of patients with SARS-CoV-2 infection. Clinical chemistry and laboratory medicine, 58(7), 1116-1120. https://doi.org/10.1515/cclm-2020-0188

He, Y., Xie, M., Zhao, J., \& Liu, X. (2020). Clinical Characteristics and Outcomes of Patients with Severe COVID-19 and Chronic Obstructive Pulmonary Disease (COPD). Medical science monitor: international medical journal of experimental and clinical research,26, e927212. https://doi.org/10.12659/MSM.927212

Holshue, M. L., DeBolt, C., Lindquist, S., Lofy, K. H., Wiesman, J., Bruce, H.,...Pallansch, M. A. (2020). Washington State 2019-nCoV Case Investigation Team. First Case of 2019 Novel Coronavirus in the United States. The New England journal of medicine, 382(10), 929-936. doi:https://doi.org/10.1056/NEJMoa2001191

Huang, C., Wang, Y., Li, X., Ren, L., Zhao, J., Hu, Y., \& Cao, B. (2020). Clinical features of patients infected with 2019 novel coronavirus in Wuhan, China. Lancet (London, England), 395(10223), 497-506. https://doi.org/10.1016/S0140-6736(20)30183-5

Ibrahim, I. M., Abdelmalek, D. H., Elshahat, M. E., \& Elfiky, A. A. (2020). COVID-19 spike-host cell receptor GRP78 binding site prediction. The Journal of infection, 80(5), 554-562. https://doi.org/10.1016/j.jinf.2020.02.026

Jaillon, S., Berthenet, K., \& Garlanda, C. (2019). Sexual Dimorphism in Innate Immunity. Clinical reviews in allergy \& immunology, 56(3), 308-321. https://doi.org/10.1007/s12016-017-8648-x

Jain, V., \& Yuan, J. M. (2020). Predictive symptoms and comorbidities for severe COVID-19 and intensive care unit admission: a systematic review and metaanalysis. International journal of public health, 65(5), 533-546. https://doi.org/10.1007/s00038-020-01390-7

Jin, Y., Yang, H., Ji, W., Wu, W., Chen, S., Zhang, W. \& Duan, G. (2020). Virology, epidemiology, pathogenesis, and control of COVID-19. Viruses. 12(4). https://doi.org/10.3390/v12040372

Kellum, J. A., van Till, J., \& Mulligan, G. (2020). Targeting acute kidney injury in COVID-19. Nephrology, dialysis, transplantation: official publication of the European Dialysis and Transplant Association - European Renal Association, 35(10), 1652-1662. https://doi.org/10.1093/ndt/gfaa231

Landry, A., Docherty, P., Ouellette, S., \& Cartier, L. J. (2017). Causes and outcomes of markedly elevated C-reactive protein levels. Canadian family 
physician Medecin de famille canadien, 63(6), e316-e323.

Lei, F., Liu, Y. M., Zhou, F., Qin, J. J., Zhang, P., Zhu, L., \& Yuan, Y. (2020). Longitudinal Association Between Markers of Liver Injury and Mortality in COVID-19 in China. Hepatology (Baltimore, Md.), 72(2), 389-398. https://doi.org/10.1002/hep.31301

Li, H., Liu, L., Zhang, D., Xu, J., Dai, H., Tang, N., Su, X. \& Cao, B. (2020). SARS-CoV-2 and viral sepsis: observations and hypotheses. Lancet. 9;395(10235):1517-1520. https://doi.org/10.1016/S0140-6736(20)30920-X

Liu, Y., Du, X., Chen, J., Jin, Y., Peng, L., Wang, H., \& Zhao, Y. (2020). Neutrophil-to-lymphocyte ratio as an independent risk factor for mortality in hospitalized patients with COVID-19. The Journal of infection, 81(1), e6-e12. https://doi.org/10.1016/j.jinf.2020.04.002

Maciel, E.L., Jabor, P., Goncalves Júnior, E., Siqueira, P.C., Prado, T.N. \& Zandonade, E. Estudo da qualidade dos Dados do Painel COVID-19 para crianças, adolescente e jovens, Espírito Santo - Brasil, 2020 (2021). Esc Anna Nery, 25(spe): e20200509. https://doi.org/10.1590/2177-9465-EAN-2020-0509

Maciel, E.L., Jabor, P., Goncalves Júnior, E., Tristão-Sá, R., Lima, RCD., Reis-Santos, B., \& Zandonade, E. (2020). Fatores associados ao óbito hospitalar por COVID-19 no Espírito Santo, 2020. Epidemiologia E Serviços de Saúde, 29, e2020413. https://doi.org/10.1590/s1679-49742020000400022

Mikami, T., Miyashita, H., Yamada, T., Harrington, M., Steinberg, D., Dunn, A., \& Siau, E. (2021). Risk Factors for Mortality in Patients with COVID-19 in New York City. Journal of general internal medicine, 36(1), 17-26. \& https://doi.org/10.1007/s11606-020-05983-z

Mizumoto, K., \& Chowell, G. (2020). Estimating Risk for Death from Coronavirus Disease, China, January-February 2020. Emerging infectious diseases, 26(6), 1251-1256. \& https://doi.org/10.3201/eid2606.200233

Ponti, G., Maccaferri, M., Ruini, C., Tomasi, A., \& Ozben, T. (2020). Biomarkers associated with COVID-19 disease progression. Critical reviews in clinical laboratory sciences, 57(6), 389-399. doi:https://doi.org/10.1080/10408363.2020.1770685

Qin, C., Zhou, L., Hu, Z., Zhang, S., Yang, S., Tao, Y., \& Tian, D. S. (2020). Dysregulation of Immune Response in Patients With Coronavirus 2019 (COVID19) in Wuhan, China. Clinical infectious diseases: an official publication of the Infectious Diseases Society of America, 71(15), 762-768. doi:https://doi.org/10.1093/cid/ciaa248

Ranzani, O. T., Bastos, L. S. L., Gelli, J. G. M., Marchesi, J. F., Baião, F., Hamacher, S. \& Bozza, F. A. (2021). Characterisation of the first 250000 hospital admissions for COVID-19 in Brazil: a retrospective analysis of nationwide data. The Lancet Respiratory Medicine, .9(4), 407-418. https://doi.org/10.1016/S2213-2600(20)30560-9

Reade, M. C., Weissfeld, L., Angus, D. C., Kellum, J. A. \& Milbrandt, E. B. (2010). The prevalence of anemia and its association with 90-day mortality in hospitalized community-acquired pneumonia. BMC Pulm Med; 10:15. https://doi.org/ 10.1186/1471-2466-10-15

Shi, Y., Wang, Y., Shao C., Huang, J., Gan, J., Huang, X., \& Melino, G. (2020). COVID-19 infection: the perspectives on immune responses. Cell Death Differ.;23:1-4. https://doi.org/ 10.1038/s41418-020-0530-3

Shi, H., Han, X., Jiang, N., Cao, Y., Alwalid, O., Gu, J., Fan, Y., \& Zheng, C. (2020). Radiological findings from 81 patients with COVID-19 pneumonia in Wuhan, China: a descriptive study. The Lancet. Infectious diseases, 20(4), 425-434. https://doi.org/10.1016/S1473-3099(20)30086-4

Shi, S., Qin, M., Shen, B., Cai, Y., Liu, T., Yang, F., \& Huang, C. (2020). Association of Cardiac Injury With Mortality in Hospitalized Patients With COVID19 in Wuhan, China. JAMA cardiology, 5(7), 802-810. doi:https://doi.org/10.1001/jamacardio.2020.0950

Snijders, D., Schoorl, M., Schoorl, M., Bartels, P. C., van der Werf, T. S., \& Boersma, W. G. (2012). D-dimer levels in assessing severity and clinical outcome in patients with community-acquired pneumonia. A secondary analysis of a randomised clinical trial. European journal of internal medicine, 23(5), 436-441. doi:https://doi.org/10.1016/j.ejim.2011.10.019\

Sousa, G., Garces, T. S., Cestari, V., Florêncio, R. S., Moreira, T., \& Pereira, M. (2020). Mortality and survival of COVID-19. Epidemiology and infection, 148, e123. doi:https://doi.org/10.1017/S0950268820001405

Tang, N., Li, D., Wang, X., \& Sun, Z. (2020). Abnormal coagulation parameters are associated with poor prognosis in patients with novel coronavirus pneumonia. Journal of thrombosis and haemostasis. JTH, 18(4), 844-847. https://doi.org/10.1111/jth.14768

Teich, V. D., Klajner, S., Almeida, F. A. S., Dantas, A. C. B., Laselva, C. R., Torritesi, M. G., \& Neto, M. C. (2020). Características epidemiológicas e clínicas dos pacientes com COVID-19 no Brasil. Einstein (São Paulo), 18, 1-7. doi:https://10.31744/einstein_journal/2020AO6022

Tian, W., Jiang, W., Yao, J., Nicholson, C. J., Li, R. H., Sigurslid, H. H., \& Malhotra, R. (2020). Predictors of mortality in hospitalized COVID-19 patients: A systematic review and meta-analysis. Journal of medical virology, 92(10), 1875-1883. doi:https://doi.org/10.1002/jmv.26050

Wang, B., Li, R., Lu, Z., \& Huang, Y. (2020). Does comorbidity increase the risk of patients with COVID-19: evidence from meta-analysis. Aging, 12(7), 6049-6057. https://doi.org/10.18632/aging.103000

Wang, C., Deng, R., Gou, L., Fu, Z., Zhang, X., Shao, F., \& Li, C. (2020a). Preliminary study to identify severe from moderate cases of COVID-19 using combined hematology parameters. Annals of Translational Medicine, 8(9), 593-593. https://doi.org/10.21037/atm-20-3391

Wang, C., Zhang, H., Cao, X., Deng, R., Ye, Y., Fu, Z., \& Lu, Z. (2020b). Red cell distribution width (RDW): a prognostic indicator of severe COVID19. Annals of translational medicine, 8(19), 1230. doi:https://doi.org/10.21037/atm-20-6090

Wang, D., Hu, B., Hu, C., Zhu, F., Liu, X., Zhang, J., \& Peng, Z. (2020). Clinical Characteristics of 138 Hospitalized Patients With 2019 Novel CoronavirusInfected Pneumonia in Wuhan, China. JAMA, 323(11), 1061-1069. https://doi.org/10.1001/jama.2020.1585

Wang, K., Zuo, P., Liu, Y., Zhang, M., Zhao, X., Xie, S., Zhang, H., Chen, X., \& Liu, C. (2020). Clinical and Laboratory Predictors of In-hospital Mortality in Patients With Coronavirus Disease-2019: A Cohort Study in Wuhan, China. Clinical infectious diseases: an official publication of the Infectious Diseases Society of America, 71(16), 2079-2088. https://doi.org/10.1093/cid/ciaa538 
Research, Society and Development, v. 11, n. 2, e25611225772, 2022

(CC BY 4.0) | ISSN 2525-3409 | DOI: http://dx.doi.org/10.33448/rsd-v11i2.25772

World Health Organization. (2021). WHO COVID-19 dashboard. World Health Organization. https://covid19.who.int/

Wu, C., Chen, X., Cai, Y., Xia, J., Zhou, X., Xu, S., \& Song, Y. (2020). Risk Factors Associated With Acute Respiratory Distress Syndrome and Death in Patients With Coronavirus Disease 2019 Pneumonia in Wuhan, China. JAMA internal medicine, 180(7), 934-943. https://doi.org/10.1001/jamainternmed.2020.0994

Xavier, A. R., Silva, J. S., Almeida, J. P. C. L., Conceição, J. F. F., Lacerda, G. S., \& Kanaan, S. (2020). COVID-19: clinical and laboratory manifestations in novel coronavirus infection. Jornal Brasileiro de Patologia E Medicina Laboratorial. https://doi.org/10.5935/1676-2444.20200049

Yang, X., Yu, Y., Xu, J., Shu, H., Xia, J., Liu, H., \& Shang, Y. (2020). Clinical course and outcomes of critically ill patients with SARS-CoV-2 pneumonia in Wuhan, China: a single-centered, retrospective, observational study. The Lancet. Respiratory medicine, 8(5), 475-481. https://doi.org/10.1016/S2213$2600(20) 30079-5$

Yi, Y., Lagniton, P., Ye, S., Li, E., \& Xu, R. H. (2020). COVID-19: what has been learned and to be learned about the novel coronavirus disease. International journal of biological sciences, 16(10), 1753-1766. https://doi.org/10.7150/ijbs.45134

Yuki K, Fujiogi M \& Koutsogiannaki S. (2020). COVID-19 pathophysiology: A review. Clin Immunol Orlando Fla. 215:108427. https://doi.org/10.1016/j.clim.2020.108427

Zhang, Y., Xiao, M., Zhang, S., Xia, P., Cao, W., Jiang, W., .\& Zhang, S. (2020). Coagulopathy and antiphospholipid antibodies in patients with COVID-19. N Engl J Med. 382(17):e38. https://doi.org/ 10.1056/NEJMc2007575

Zhang, C., Shi, L., \& Wang, F. S. (2020). Liver injury in COVID-19: management and challenges. The lancet. Gastroenterology \& hepatology, 5(5), 428-430. https://doi.org/10.1016/S2468-1253(20)30057-1

Zhang, J. J., Dong, X., Cao, Y. Y., Yuan, Y. D., Yang, Y. B., Yan, Y., \& Gao, Y. D. (2020). Clinical characteristics of 140 patients infected with SARS-CoV2 in Wuhan, China. Allergy, 75(7), 1730-1741. https://doi.org/10.1111/all.14238

Zhou, F., Yu, T., Du, R., Fan, G., Liu, Y., Liu, Z., \& Cao, B. (2020). Clinical course and risk factors for mortality of adult inpatients with COVID-19 in Wuhan, China: a retrospective cohort study. Lancet (London, England), 395(10229), 1054-1062. https://doi.org/10.1016/S0140-6736(20)30566-3 